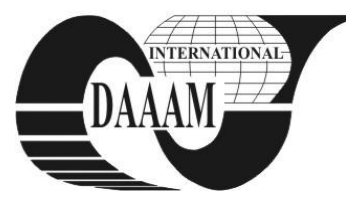

Annals of DAAAM for 2011 \& Proceedings of the 22nd International DAAAM Symposium, Volume 22, No. 1, ISSN 1726-9679 ISBN 978-3-901509-83-4, Editor B. Katalinic, Published by DAAAM International, Vienna, Austria, EU, 2011 Make Harmony between Technology and Nature, and Your Mind will Fly Free as a Bird Annals \& Proceedings of DAAAM International 2011

\title{
METHODOLOGY OF TEACHING 3D DESIGN
}

\author{
SUKA, P[redrag]
}

\begin{abstract}
In today's world of stunning visual effects and artwork it's at times impossible to determine the virtual Computer-generated imagery (later referred as CGI), from the real models and live footage. This paper tackles ways that define best possible approaches in giving knowledge of $3 D$ design, making one receiving aforesaid grow from a regular viewer to a $3 D$ artist. Ways of visually presenting each step in teaching, defining concepts with live examples, researching proven techniques and time management during learning process for far better understanding. Without proper guidance, defined goals and clear concepts that can be given when firstly encountering $3 D$ design via a course learning experience, all that could be most easily defined as "per aspera ad astra".

Key words: methodology, teaching, $3 D$ design, concepts, perception
\end{abstract}

\section{INTRODUCTION}

An adage "A picture is worth a thousand words" deserves an upgrade in it's definition or a complete new connotation. It's extremely rare in 3D design and photography in it's now best perceived digital form, that a single image is just a single image or single layer of information. Whether we're talking about a still or an animation the rules and best known practices are the same. Both are usually comprised out of numerous imagery that when combined establish a visual code that we perceive as realistic, artistic or other applicable style of visual form.

The complexity of aforesaid is visible in most of visuals we're faced, ranging from movies, TV shows, broadcasting, all the way to graphic, web design and CGI artworks. 3D design and it's implications are very powerful means that can alter ones perception, describe it with precision and ease once complicated terms. Following figure represents breakdown of $21^{\text {st }}$ second in the postproduction phase of a Black Beetle commercial done by The Mill for Deutch Agency.

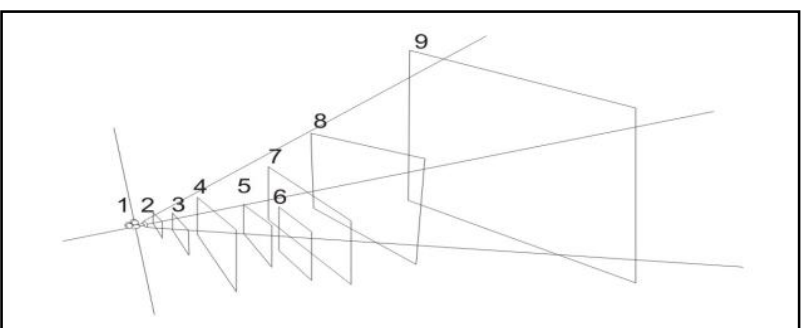

Fig. 1. Scheme of 3D design in video postproduction. From left to right composition of layers representing the final without visible after effects: 1 . camera (point of view), 2. - 6 . foreground layers, 7. main focus layer, 8. and 9. background elements.

After assembling all the layers, with given values such as transparencies (alpha channel), depth of field, individual and overall colour correction, blending modes and slight lens flare and vignette, the final shot goes that extra length in describing few thousand words rather than what aforesaid adage describes.

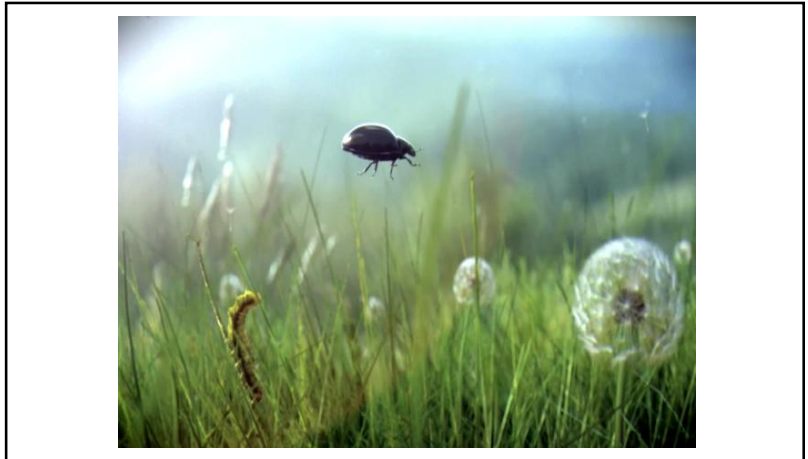

Fig. 2. Black Beetle commercial, The Mill, 2011. The figure shows one final frame from $21^{\text {st }}$ second of the commercial (http://www.themill.com/work/volkswagen/black-beetle.aspx).

Everything stated and much more that will be discussed further in this paper, presents a problem within initial contact with 3D design. Getting the point across was never harder and easier at the same time. Harder due to it's complexity, and easier because everything is visual, all the calculations and automations are left for the software to handle, bearing in mind that $3 \mathrm{D}$ designer and/or artist knows the end goal and can take appropriate steps in achieving it.

\section{ISSUES IN UNDERSTANDING 3D DESIGN}

Majority of the problems can be summed up in inability to see the end result when speaking about individual components of 3D design. Most of the online courses in 3D design and it's practical implications in different fields often get caught up in explanations of software, pipelines and the technical sides, rather than tackling aspects of each element in 3D design that alter one another's appearance. If we consider making a 3D model as a start of an idea, one can spend a significant amount of time defining it's shape and form, but alternatively can express certain areas with smart use of textures. If we for the time being disregard the bond between 3D models and textures through proper combination of coordinates, the effect of textures falls under the influence of proper use of materials, shaders and render engines. Summing it up textures depend on at least four aforesaid elements in order to be represented in the manner in which they were designed. However when looking at the entire process we can't disregard cameras and lights nor animation effects if applicable to the 3D model/design at hand. This is now becoming complex to a point where it's hard to keep up which element is determining which elements behaviour and effect. For the most part a simple lack of visual aids in the course of teaching represents the biggest setback when tackling the ability to understand 3D design and it's key elements. An easy task when given the solution in a form of visual representation, but a hard or nearly impossible one when trying to connect every possible outcome, variable and state one can find upon learning or working within 3D design. 


\section{METHODOLOGY OF TEACHING 3D DESIGN}

The best way of teaching 3D design relies on following theoretical and practical knowledge by visual representation of possible outcomes. However strenuous it may be, when given knowledge is supported by it's result in a form of CGI, the perception and notion of it, is deepened and strengthened. At times it's hard to address to every piece of information with a visual aid and it certainly lengthens the time of lectures and overall process of attaining knowledge. So to combat that problem, visual results and tests on the scene can be replaced by explanations to what results given knowledge and examples may lead. Having said that, information spoken must often be repeated in order to be perceived and memorised. In two years of teaching in this field at Algebra d.o.o. I've used official training and marketing video and webinar clips, professional still and video breakdowns and personal CGI created for the sole purpose to corroborate knowledge given via different approaches and workflows when describing each step in 3D design. Combination of constantly giving options and possible outcomes with still or animated visuals, proved to be successful in the way the knowledge is comprehended and reproduced later on during class and during exams. Explanations of certain practices changes as the software tools change and upgrade, but methodology stays the same.

Within the whole process of teaching, motivation should be the key factor, and not only applicable to 3D design. But when looking at it in the current field, motivating a person to begin exploring and creating his or her very own CGI, often leads to many unanswered questions. Those unanswered questions lead to answers and those answers to progress. Careful approach should be implemented since presenting brilliant CGI artwork or similarly impressive implementation of 3D design may have an opposite effect to aforesaid motivation. Hence the emphasis should be on the ease of creation and not it's complexity at the beginning. Telling the visual story how a simple AO (Ambient occlusion - may lead to a better and much more realistic visual results. Or in the same manner presenting how to benefit from using depth of field that has long been a code, photography has present in her every field and most profoundly and clearly in macro photography. Reaching a state of photorealism is not an easy path, but knowing which combination will lead a step closer is something to focus on and something worth defining as clearly and directly as possible.

Following figure shows how a combination of eight individual layers lead to a single CGI, each of which convey new look and feel. Every element can be easily addressed and activated providing visual information of its influence.

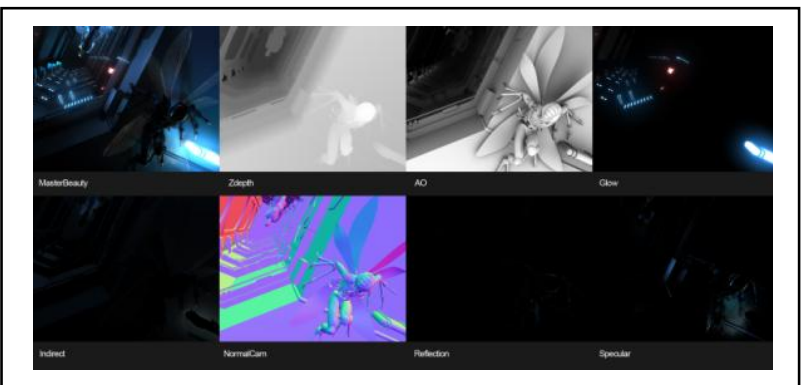

Fig. 3. "Insectoid" breakdown to individual elements. From left to right, upper to bottom row: Master Beauty, Zdepth, AO, Glow, Indirect, Normal Camera, Reflection, Specular.

Successful combination is not only the result, but it also represents the flexibility to alter the final look by changing parameters of just one element or effect. Showing that power often leads to best knowledge, since the one learning alters parameters and options in his own way and style; concluding that every combination leads to a diffetent outcome.

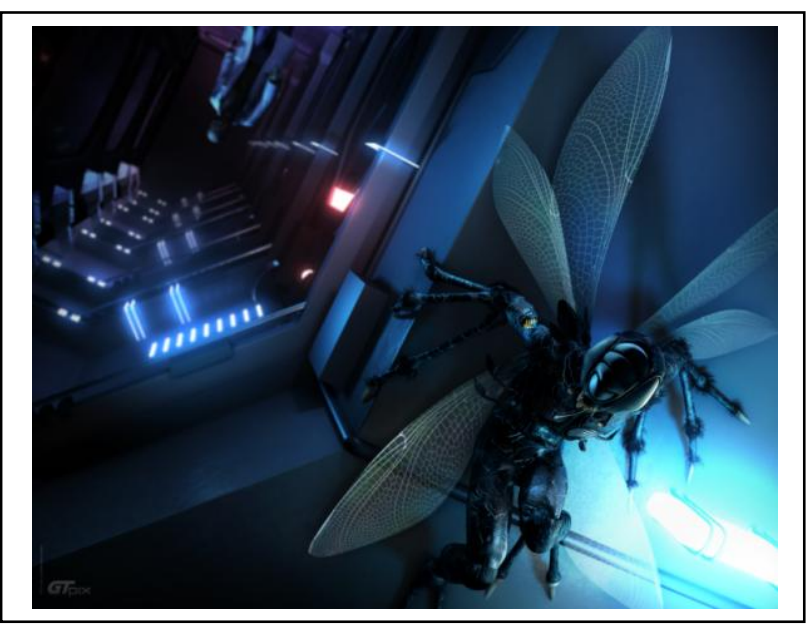

Fig. 4. "Insectoid" - finished artwork.

\section{INTENDED FUTURE DEVELOPMENT IN METHODOLOGY}

Making a highly detailed scheme of every element in 3D design and it's link, correlation and how it affects others would, to best of judgment, prove to be a guide to a better learning curve and experience. A sort of a mind mapping guide to what if scenarios and possible outcomes. Added value would be information about tools that may be of some added benefit when compared to others, or a simple list that would narrow the focus and shorten unnecessary research.

\section{CONCLUSION}

Knowing basic principles of art and it's growth plays a vital role in preparation for 3D design overall that tries to mimic it. Advantages of 3D design are that specter by which you can build CGI and ways of presenting aforesaid almost knows no bounds. With every new advancement in the industry where 3D design is implemented, we become speechless, especially if we look at it's most diverse field, film (Suka, 2011).

This familiarity provides a wide range of examples to choose from. Actually those are the best examples since they already have a huge impact on our perception, and when we break them down to elements, cause and effect, knowledge then given already has a better chance of being properly perceived.

3D design isn't prone to a common belief in talent, and maybe we can agree that talent is only a predisposition, and not a virtue that itself can produce results worth admiration. Proper use of knowledge and huge amounts of effort can (Suka, 2011).

\section{ACKNOWLEDGEMENTS}

I would like to thank 3DTotal.com Ltd for being a vital part of my professional growth and Algebra d.o.o. for the freedom to create, teach and evolve.

\section{REFERENCES}

Suka, P. (2011), Overview of 3D Design, Algebra, ISBN: 978953-322-072-7, Zagreb

Cusson, R. (2009), Learning Autodesk 3ds Max 2010, Autodesk, ISBN: 978-0-240-81193-2, Oxford

Thomas, C., Neale, P., Thistlethwaite, S., Qwek, D., CG Academy Complete Training, Available from: http://www.cg-academy.net/, Accessed: 2011-07-01

Smith, B., Gorbunov, A., 3ds Max course recornings, Available from: http://www.thecgschool.com/, Accessed: 2011-07-01

Nelle, S., Ross, A.F., 3ds Max 2011 training, Available from: http://www.lynda.com/, Accessed: 2011-07-01 